\title{
PERSENTASE PEDICULOSIS CAPITIS PADA ANAK USIA 9-12 TAHUN DI RW XI KAMPUNG GAMPINGAN KOTA YOGYAKARTA
}

\author{
Nurlaili Farida Muhajir'1, Desto Arisandi², Yuliana Prasetyaningsih ${ }^{3}$ \\ ${ }^{1,2,3}$ D3 Analis Kesehatan STIKes Guna Bangsa Yogyakarta
}

\begin{abstract}
Background : Pediculosis capitis disease can be found all over the world without the restrictions of age, gender, race, economic status, and social status. Pediculosis capitis mainly affects young children and quickly spread in a dense environment such as dorm, orphanages, large cities and densely populated elementary school with bad hygiene, such behavior is rarely clean the hair. Factors that can help spread Pediculus humanus capitis infestation is socio-economic factors, level of knowledge, personal hygiene, environment, and individual characteristics (age, hair length, and hair type).
\end{abstract}

Methods : This was descriptive study. The population in this study was children who were stayed in kampung Gampingan kota Yoyakarta. Sample was taken by purposive sampling with criteria of inclusion and exclusion. The instrument used laboratory examination about Pediculus humanus capitis with direct examination. Analysis of data used univariate analysis.

Result \& Conclusion : Pediculosis capitis children who have age 9-12 years in Kampung Gampingan RW XI Yogyakarta was $86.84 \%$.

Keywords : Pediculosis capitis, Population density

\section{PENDAHULUAN}

Penyakit Pediculosis capitis dapat ditemukan di seluruh dunia tanpa adanya batasan umur, jenis kelamin, ras, status ekonomi, dan status sosial. Prevalensi dan insidensi Pediculosis capitis di seluruh dunia cukup tinggi, diperkirakan ada ratusan juta orang yang terinfeksi Pediculosis capitis setiap tahunnya. Sekitar 6-12 juta anak usia 3-11 tahun terinfeksi Pediculus humanus capitis setiap tahunnya di Amerika Serikat, sedangkan menurut data di Belgia terdapat sekitar 6.169 anak usia 2.5-12 tahun yang terinfeksi. Penelitian pediculosis di rumah sakit Dr.Soetomo Surabaya menunjukkan penderita Pediculosis 0,5\% pada tahun 1999-2003. Hasil penelitian telah menemukan insiden pedikulosis kapitis pada anak sekolah dasar umur 8-12 tahun di desa sebesar $1,59 \%$ dan sekolah dasar di kota ditemukan sebanyak 0,48\% (Buczek dkk, 2003). Pediculosis capitis terutama menyerang anak-anak usia muda dan cepat meluas dalam lingkungan hidup yang padat misalnya asrama, panti asuhan, kotakota besar yang berpenduduk padat dan sekolah dasar dengan hygiene yang tidak 
baik, misalnya perilaku jarang membersihkan rambut (Novriadi, 2012).

Faktor yang dapat membantu penyebaran infestasi Pediculosis capitis adalah faktor sosial-ekonomi, tingkat pengetahuan, higiene perorangan, lingkungan, dan karakteristik individu (umur, panjang rambut, dan tipe rambut). Gejala yang timbul akibat infestasi Pediculosis capitis adalah rasa gatal akibat dari gigitan kutu. Pediculus capitis yang tidak diobati dapat menimbulkan berbagai dampak pada penderita Pediculosis capitis, antara lain berkurangnya kualitas tidur anak pada malam hari akibat rasa gatal, stigma sosial, rasa malu dan rendah diri (Djuanda, 2010).

Kutu rambut kepala lebih suka berkembang biak pada rambut kepala yang kotor, lembab, jarang disisir dan dikeramas. Kutu rambut kepala dapat bergerak dengan cepat dan mudah berpindah dari satu hospes ke hospes lain. Mudah ditularkan melalui kontak langsung atau dengan perantara barang-barang yang dipakai bersama-sama. Misalnya sisir, sikat rambut, topi dan lain-lainnya. Sangat banyak ditemukan diantara anak sekolah terutama gadis-gadis yang kurang menjaga kebersihan rambut kepala (Djuanda, 2010).

Lingkungan yang padat merupakan lingkungan yang kurang kondusif bagi manusia. Karena lingkungan yang padat dapat menyebabkan penurunan kesehatan baik kesehatan fisik maupun kesehatan mental. Lingkungan yang padat disebabkan oleh perkembangan masyarakat yang bertambah pesat dan pada akhirnya menyebabkan kesesakan. Dari pertumbuhan masyarakat yang begitu meningkat mengakibatkan kegiatan dari setiap individu juga meningkat (Anggi, 2005).

\section{METODE PENELITIAN}

Jenis penelitian yang dipakai adalah deskriptif yaitu peneliti hanya melakukan observasi dan pengukuran variabel pada satu saat itu juga. Pengukuran variabel tidak terbatas harus tepat dan pada satu waktu bersamaan, namun mempunyai makna bahwa setiap subyek hanya dikenai satu kali pengukuran. Subyek dalam penelitian ini adalah anak usia 9-12 tahun yang tinggal di RW XI Kampung Gampingan Kota Yogyakarta. Penelitian ini populasinya heterogen dengan kriteria inklusi yaitu jenis kelamin perempuan, umur berkisar antara 9-12 tahun dan bersedia menjadi responden.

Cara pengambilan data pada penelitian ini adalah dengan pemeriksaan langsung dengan menggunakan alat serit pada subyek peneliti yang memenuhi kriteria inklusi.

\section{HASIL DAN PEMBAHASAN \\ A. HASIL}

Tabel 1. Distribusi Frekusensi Jumlah Penduduk kelurahan Pakuncen Menurut Usia

\begin{tabular}{llll}
\hline No & Kelompok Umur & Frekuensi & $\%$ \\
\hline 1 & $0-3$ Tahun & 577 & $5,0 \%$ \\
\hline 2 & 4 - 6 Tahun & 504 & $4,4 \%$ \\
\hline 3 & 7 - 12 Tahun & 1.943 & $17,1 \%$ \\
\hline 4 & 13 - 15 Tahun & 555 & $4,8 \%$ \\
\hline 5 & $16-18$ Tahun & 348 & $3,0 \%$ \\
\hline 6 & >19 Tahun & 7.403 & $65,3 \%$ \\
\hline & Jumlah & 11.33 & $100 \%$ \\
\hline
\end{tabular}

Sumber: Data sekunder, 2012 
Dapat diketahui dari Tabel 1 bahwa jumlah penduduk menurut usia dengan persentase tinggi di Kelurahan Pakuncen adalah usia diatas 19 tahun yaitu sebesar $65,3 \%$, sedangkan usia 7-12 tahun menempati urutan ke dua setelah usia diatas 19 tahun yaitu sebesar $17,1 \%$. Tabel tersebut juga dapat menunjukkan jumlah penduduk Kelurahan Pakuncen dengan prosentase rendah adalah usia 16- 18 tahun yaitu sebesar 3,0\%. Kriteria inklusi yang dipakai oleh peneliti yaitu umur 9-12 tahun, berjenis kelamin perempuan, bertempat tinggal di RW XI Kampung Gampingan Kota Yogyakarta dan bersedia menjadi responden peneliti.

Tabel 2. Data Jumlah Penduduk Usia 9-12 tahun di RW XI Kampung Gampingan Kelurahan Pakuncen

\begin{tabular}{cc}
\hline RT & Jumlah \\
\hline 48 & 6 \\
\hline 49 & 12 \\
\hline 50 & 8 \\
\hline 51 & 16 \\
\hline & \\
Jumlah & 42 \\
\hline
\end{tabular}

Sumber: Data primer, 2013

Dari Tabel 2 dapat diketahui bahwa RW XI memiliki 4 RT yang terdiri dari RT 48, 49, 50, 51. Jumlah anak usia 9-12 tahun yang terbanyak dimiliki oleh RT 51 yaitu 16 anak, sedangkan RT 48 memiliki jumlah anak usia 9-12 tahun terendah. Penelitian ini hanya mengambil 38 anak usia 9-12 tahun sebagai sampel yang sesuai dengan kriteria inklusi dan bersedia menjadi responden yang telah ditentukan, sedangkan ada 4 anak usia 9-12 tahun yang memenuhi kriteria inklusi tetapi tidak bersedia menjadi responden tidak diperiksa.

Tabel 3: Distribusi Frekuensi Infeksi Pediculus humanus capitis

\begin{tabular}{|c|c|c|c|}
\hline No & $\begin{array}{l}\text { Infeksi Pediculus } \\
\text { humanus capitis }\end{array}$ & Frekuensi & $\%$ \\
\hline 1 & Positif & 33 & 86,84 \\
\hline 2 & Negatif & 5 & 13,16 \\
\hline & Jumlah & 38 & 100 \\
\hline
\end{tabular}

Sumber: Data primer, 2013

Tabel 3 di atas menunjukkan 86,84\% anak usia 9-12 tahun yang dijadikan sampel dalam penelitian ini di RW XI Kampung Gampingan Kecamatan Wirobrajan Kota Yogyakarta terinfeksi Pediculus humanus Capitis. Prosentase ini jauh lebih tinggi dibandingkan dari anak yang tidak terinfeksi yaitu sebesar 13,16\%. Dari jumlah 38 anak usia 9-12 tahun yang dijadikan sampel dalam penelitian ini di RW XI Kampung Gampingan Kota Yogyakarta terinfeksi Pediculus humanus capitis sebesar 33 anak, sedangkan yang tidak terinfeksi Pediculus humanus capitis hanya 5 anak.

\section{B. PEMBAHASAN}

Subyek yang digunakan dalam penelitan ini adalah anak usia 9-12 tahun di Kampung Gampingan RW XI Kecamatan Wirobrajan Kota Yogyakarta yang berjenis kelamin perempuan, berusia 9-12 tahun, bertempat tinggal di Kampung Gampingan RW XI dan bersedia menjadi responden. Usia 9-12 tahun merupakan masa-masa yang sangat peka menerima perubahan atau pembaharuan, karena kelompok anak usia ini sedang berada dalam taraf pertumbuhan dan perkembangan. Menurut Noor (2008) 
beberapa penyakit menular tertentu menunjukkan bahwa umur muda mempunyai risiko yang tinggi, bukan saja karena tingkat kerentanannya, melainkan juga pengalaman terhadap penyakit tertentu yang biasanya sudah dialami oleh mereka yang berumur lebih tinggi.

Kampung Gampingan memiliki lokasi yang berada di tengah Kota Yogyakarta dan berdekatan dengan pasar Kepadatan penduduk dan kurangnya kebersihan lingkungan mempengaruhi kesehatan baik secara langsung maupun tidak langsung khususnya terhadap warga Kampung Gampingan RW XI. Lingkungan yang padat merupakan lingkungan yang kurang kondusif bagi manusia. Lingkungan yang padat dapat menyebabkan penurunan kesehatan baik kesehatan fisik maupun kesehatan mental. Hal ini berdampak negatif dan telah dibuktikan dari beberapa penelitian sebelumnya.

Hasil penelitian dari 38 sampel anak usia 9-12 tahun yang bersedia menjadi responden ternyata $86,84 \%$ terinfeksi Pediculus humanus capitis. Persentase yang tinggi dikarenakan kepadatan penduduk di Kampung Gampingan RW XI yang cukup tinggi, dapat dilihat dari data hasil observasi bahwa dari 38 anak usia 912 tahun yang diteliti dan bersedia menjadi responden sebanyak $86,84 \%$ yang terinfeksi Pediculus humanus capitis.

Kejadian Pediculosis capitis pada penelitian sesuai dengan penelitian Restiana (2010) di Yogyakarta dengan subjek penelitian berjumlah 80 anak. Penelitian dilakukan di asrama yang berada di Yogyakarta. Penelitian ini menunjukkan adanya hubungan yang signifikan antara kejadian Pediculosis capitis dengan kepadatan hunian dan higiene pribadi. Kesulitan penelitian ini adalah sulitnya meyakinkan anak usia 9-12 tahun untuk menjadi responden serta bersedia untuk diperiksa, pengambilan data kependudukan RW XI kampung Gampingan dan peneliti tidak mengukur kepadatan penduduk tinggi dan kepadatan penduduk rendah di lokasi lain.

Sebagian besar anak usia 9-12 tahun tidak mengetahui bahwa infeksi Pediculus humanus capitis yang tinggi di suatu daerah dapat menyebabkan dampak yang serius misanya penurunan prestasi belajar anak yang diakibatkan rasa gatal yang terus menerus saat belajar dan penyebaran infeksi Pediculus humanus capitis yang cepat sehingga dapat dengan mudah menyebar luas dalam lingkungan di sekitarnya. RW XI Kampung Gampingan memiliki jumlah penduduk 637 jiwa dengan luas wilayah $4 \mathrm{Ha}$, ini menunjukan bahwa kepadatan penduduk RW XI Kampung Gampingan adalah 160 Jiwa/ Ha atau dapat dikatakan kepadatan pendudguk sedang. Data kependudukan sebagian diambil dari kantor kelurahan yang mencakup satu kelurahan yang terbagi menjadi $12 \mathrm{RW}$ dan $56 \mathrm{RT}$, sedangkan jumlah penduduk dalam satu kelurahan adalah 11.330 jiwa dengan jumlah lakilaki 5.593 jiwa dan perempuan 5.737 jiwa. Kelurahan Pakuncen memiliki kepadatan penduduk $17.431 \quad \mathrm{~km}^{2} /$ jiwa ini menunjukkan bahwa kepadatan penduduk di Kelurahan Pakuncen termasuk dalam katagori kepadatan penduduk sedang.

\section{KESIMPULAN DAN SARAN A. KESIMPULAN}

1. Persentase Pediculosis capitis di RW XI Kampung Gampingan Kota Yogyakarta pada anak usia 9-12 tahun sebesar 86,84\%.

2. Kepadatan penduduk di RW XI Kampung Gampingan Kota Yogyakarta 
masuk dalam kategori kepadatan penduduk sedang dengan jumlah kepadatan penduduk $160 \mathrm{jiwa} / \mathrm{Ha}$.

\section{B. SARAN}

1. Bagi Peneliti

Perlu diadakan penelitian lanjut dengan menyertakan data kependudukan yang lebih terperinci dan dapat melakukan penelitian Pediculosis capitis pada anak usia 9-12 tahun di lokasi yang memiliki kepadatan penduduk tinggi dan rendah.

2. Bagi Masyarakat

Memberikan informasi bagi masyarakat Indonesia dan khususnya bagi warga RW XI Kampung Gampingan Kota Yogyakarta dapat mengobati dan mencegahin feksi Pediculus humanus capitis pada anak usia 9-12 tahun yang terinfeksi Pediculus humanus capitis agar tidak cepat menyebar luas ke wilayah lain.

3. Bagi Sekolah Tinggi Ilmu Kesehatan Guna Bangsa Yogyakarta

Hasil Karya Tulis Ilmiah ini sebaiknya dapat digunakan untuk referensi dan menambah koleksi perpustakaan sehingga dapat bermanfaat untuk bacaan mahasiswa khususnya bagi mahasiswa STIKes Guna Bangsa Yogyakarta.

\section{DAFTAR PUSTAKA}

Attonk, 2009, Hubungan Pediculosis capitis dengan sanitasi lingkungan, Jurnal Makara Kesehatan, Vol. 8, No. 5, April 2009

Buczek, 2003. Kesehatan Lingkungan. FKM-UI. Jakarta.
Depkes RI, 2004. Pedoman Program Nasional Pemberantasan Cacingan di Era Desentralisasi, Direktorat Jendral Pemberantasan Penyakit Menular dan Penyehatan Lingkungan, Jakarta.

Djuanda, 2010. Ilmu penyakit kulit dan kelamin. Edisi 6. Jakarta: FKUI.

Fitzpatrick, 2008. Penggunaan Obat Rasional, Departemen Farmakologi Fakultas Kedokteran Universitas Indonesia, Jakarta, Jurnal Indon Med Assoc, Vol. 61 No. 4, April 2008.

Kretif, 2010. Geografi SMA /MA kelas XI. Jakarta: PT. Bumi Aksara.

Mansjoer, 2000. Kapita selekta kedokteran. Edisi 3, jlid 3. Jakarta: Media Aesculapius.

Meta, 2011. Masalah Kepadatan Penduduk. dari http://www.jawaposting.blogspot.com/201 1/04/masalah-kepadatan-penduduk.html. Diunduh tanggal 23 Februari. Yogyakarta.

Noor, 2008. Epidemiologi, Edisi Revisi, Rineka Cipta; Jakarta.

Notoatmodjo, 2005. Metodologi Penelitian Kesehatan, Rineka Cipta, Jakarta.

Nuraini, 2004. Pemberantasan Arthopoda yang penting dalam hubugan dengan kesehatan masyarakat. USU digital library. Sumatera Utara.

Resti, 2010. Hubungan berbagai faktor resiko terhadap angka kejadian pedikulosis capitis di asrama. Under Graduates Tesis, Fakultas Kesehatan, Universita Muhammadiyah Yogyakarta. 
Shinta, 2008. Kutu rambut. dari http://www.studiku.com/2008/09/05/pedic ulus-humanus-capitis-kutu-rambut/.

Diunduh tanggal 24 Oktober 2012. Yogyakarta.

Suhaeni, 2011. Kepadatan penduduk dan hunian di lingkungan perumahan padat, Jurnal Vol.6. No. 2.

Sunyoto, 2012. Statistik Kesehatan, Cetakan I, Nuha Medika: Yogyakarta.

Sutanto, 2008. Pediculosis. Buku ajar kedokteran edisi 4: Jakarta : FKUI.

Wulan, 2009. Survei Pediculus humanus capitis dan Perilaku Menjaga Kebersihan Rambut Pada Anak Sekolah Dasar, Jurnal Kesehatan Vol. 4. No. 3 September 2007. 